\title{
A fotografia no discurso sobre o ensino de jornalismo no Brasil na primeira metade do século XX
}

\author{
Photography in brazilian teaching journalism speech in the first half of the 20th century \\ La fotografía en el discurso sobre la enseñanza del periodismo en Brasil en la primera mitad del \\ siglo XX
}

Recebido: 16/06/2021 | Revisado: 22/06/2021 | Aceito: 24/06/2021 | Publicado: 30/07/2021

\author{
Agda Patrícia Pontes de Aquino \\ ORCID: https://orcid.org/0000-0001-9667-0903 \\ Universidade Estadual da Paraíba, Brasil \\ Universidade Federal da Paraíba, Brasil \\ E-mail: profagdaaquino@gmail.com
}

\begin{abstract}
Resumo
Recorrendo à proposta teórico-metodológica da Análise Arqueológica do Discurso, do filósofo francês Michael Foucault (2005), o trabalho se debruça sobre o discurso de seis intenções pedagógicas para o ensino de jornalismo surgidas na primeira metade do século passado, entre 2018 e 1950, aproximadamente. Nelas, busca-se identificar o lugar discursivo ocupado pela fotografia, através das ferramentas de análise oferecidas pela Arqueologia do Discurso. São analisadas seis intenções curriculares deste período que antecede a oficialização dos cursos superiores para a formação em jornalismo no Brasil, o que se efetiva apenas em 1950. O acesso a esses documentos foi dato pela da obra de Dias (2018), que fez um levantamento sobre as origens do ensino de jornalismo no país. Mesmo que a maioria desses currículos não tenha entrado em funcionamento, eles demonstram que a fotografia já era compreendida como algo importante para a formação em jornalismo desde 1918, se contrapondo ao que está posto nas atuais Diretrizes Curriculares Nacionais para os cursos de jornalismo, publicadas em 2013, que deixaram a fotografia fora de suas linhas.
\end{abstract}

Palavras-chave: Fotografia; Ensino; Jornalismo; Cursos; Diretrizes.

\begin{abstract}
Through the theoretical-methodological proposal of Archaeological Discourse Analysis, by the French philosopher Michael Foucault (2005), the work focuses on the discourse of six pedagogical intentions for the teaching of journalism that emerged in the first half of the last century, between 2018 and 1950. In them, we seek to identify the discursive place occupied by photography, through the analysis tools offered by Discourse Archeology. Six curricular intentions from this period that precede the officialization of higher education courses in journalism in Brazil are analyzed, which only occurred in 1950. Access to these documents was given through the work of Dias (2018), who carried out a survey about the origins of journalism education in the country. Even though most of these curricula have not come into operation, they demonstrate that photography was already understood as something important for study in journalism since 1918, in opposition to what is stated in the current National Curriculum Guidelines for journalism courses, published in 2013, which left photography out of its lines.
\end{abstract}

Keywords: Photography; Teaching; Journalism; Courses; Guidelines.

\section{Resumen}

Utilizando la propuesta teórico-metodológica del Análisis Arqueológico del Discurso, del filósofo francés Michael Foucault (2005), el trabajo se centra en el discurso de seis intenciones pedagógicas para la enseñanza del periodismo surgidas en la primera mitad del siglo pasado, entre 2018 y 1950, aproximadamente. En ellos, buscamos identificar el lugar discursivo que ocupa la fotografía, a través de las herramientas de análisis que ofrece la Arqueología del Discurso. Se analizan seis intenciones curriculares de este período que preceden a la oficialización de los cursos de educación superior para la formación en periodismo en Brasil, que solo tuvo lugar en 1950. El acceso a estos documentos se dio a través del trabajo de Dias (2018), quien realizó una encuesta sobre los orígenes de la educación periodística en el país. Si bien la mayoría de estos planes de estudio no han entrado en funcionamiento, demuestran que la fotografía ya se entendía como algo importante para la formación en periodismo desde 1918, en contraposición a lo expresado en los actuales Lineamientos Curriculares Nacionales para cursos de periodismo, publicados en 2013, que dejó la fotografía fuera de sus líneas.

Palabras clave: Fotografía; Enseñando; Periodismo; Cursos; Pautas. 


\section{Introdução}

O jornal $O$ Besouro, uma folha ilustrada criada em 1878 no Rio de Janeiro, publicou provavelmente as primeiras fotografias de cunho jornalístico na imprensa brasileira (Buitoni, 2010). Em 1900 o suplemento intitulado Revista da Semana, do Jornal do Brasil, também trazia fotografias impressas em suas páginas (Louzada, 2004). Alguns anos depois, praticamente todos os jornais diários do país já eram ilustrados fotograficamente. É nesse período que surgem as primeiras propostas pedagógicas para o ensino de jornalismo no país, que era uma profissão consagrada porém ocupada por pessoas sem qualquer tipo de formação ou pelos bacharéis em outras áreas, como direito, por exemplo (Dias, 2018). Nos anos 1940 já existiam grandes fotorreportagens em publicações ilustradas de tiragem em massa, como na revista $O$ Cruzeiro, utilizando material imagético extenso e de relevante conteúdo informacional. Desde esse período, a utilização de imagens jornalísticas nos meios de comunicação só cresce, numa exponencial nunca antes imaginada, especialmente após o advento da fotografia digital (Buitoni, 2011).

Apesar da importância histórica e contemporânea da imagem fotográfica na imprensa brasileira, a fotografia ficou ausente das Diretrizes Curriculares Nacionais para os cursos de Jornalismo (BRASIL, 2013), colocando o fotojornalismo em um lugar marginal no ensino de jornalismo no Brasil. Nenhum trecho do documento traz qualquer menção à imagem fotográfica. Essa ausência pode ser compreendida no fragmento de texto que detalha o eixo de aplicação processual, no qual outras áreas de atuação são nomeadas, com a ausência da fotografia.

V - Eixo de aplicação processual, cujo objetivo é o de fornecer ao jornalista ferramentas técnicas e metodológicas, de modo que possa efetuar coberturas em diferentes suportes: jornalismo impresso, radiojornalismo, telejornalismo, webjornalismo, assessorias de imprensa e outras demandas do mercado de trabalho (BRASIL, 2013, p. 5).

Algumas das possíveis consequências dessa exclusão da fotografia das atuais DCNs foram abordadas por Aquino (2018), numa compreensão de que essa ausência provoca uma "dificuldade no entendimento do fotojornalismo enquanto área de trabalho do jornalista profissional e da fotografia enquanto linguagem da informação jornalística" (Aquino, 2018, p. 1). A ausência da fotografia nas atuais DCNs também serviu como ponto de partida para a tese de doutorado intitulada "Uma arqueologia do discurso sobre o ensino de fotografia no bacharelado em jornalismo no Brasil: o status marginal do fotojornalismo" (Aquino, 2021), que traça o percurso do discurso sobre a fotografia numa vasta documentação sobre o ensino de jornalismo no país, abordando fontes regimentais, legais e pedagógicas que datam de 1918 a 2018.

A falta de referência à fotografia nas atuais DCNs vai de encontro também ao perfil de trabalho do jornalista brasileiro. A ampla pesquisa realizada no país em 2012 (Mick; Lima, 2013), mostra que 35,4\% dos jornalistas que trabalham diretamente com a mídia incluem a fotografia nas suas atuações e que quase metade dos profissionais de jornalismo que trabalham fora da mídia (47,8\%), como em assessorias de imprensa, por exemplo, também produzem imagens fotográficas em seu trabalho jornalístico. A ausência da fotografia nas DCNs atuais contradiz ainda o histórico do ensino de jornalismo no país, que desde suas primeiras intenções pedagógicas, passando pela consolidação dos cursos superiores, incluíram a fotografia como uma das áreas importantes de atuação profissional, a exemplo dos currículos mínimos de 1969 até 1984, que contam com a presença da fotografia ou do fotojornalismo em todas as suas versões.

Objetivando um futuro onde o fotojornalismo seja compreendido com status de igualdade em relação a outras áreas de atuação profissional pela legislação educacional e pela sua aplicação em projetos pedagógicos com a importância que tem no mercado profissional, voltamos o olhar ao passado para buscar, nas primeiras propostas pedagógicas para o ensino de jornalismo no país, uma maneira diferente de compreender o ensino de fotografia para esta profissão. Como afirma McLuhan (1977), o passado é como um espelho retrovisor que mostra o que está por vir e não apenas o que passou, vislumbra possibilidades para o que está pela frente. Portanto é objetivo deste artigo trazer à luz a compreensão discursiva que os 
primeiro projetos pedagógicos do país tinham sobre a fotografia, num contexto histórico analisado à luz da arqueologia do discurso de Foucault (2005), visando encontrar ideias pedagógicas que sirvam para o futuro.

\section{Metodologia}

A Análise Arqueológica do Discurso (AAD) aborda o passado com uma perspectiva bastante específica, se atendo em detalhes ao que está posto nas fontes analisadas, num processo intenso de escavação, cruzando discursos que atravessam o tempo e identificando os nós que entrelaçam a rede discursiva e produzem enunciados que são perpetuados ou esquecidos. Dentro da espessura histórica, a AAD busca identificar correlatos, elencar discursos, pontuar ausências e presenças, afastando o pesquisador de opiniões ou interpretações pessoais para dar destaque ao que está presente nos documentos estudados.

Os estudos baseados na AAD se ocupam em analisar, descrever e explicitar as especificidades discursivas que compõem a teia de relações de um enunciado, uma espécie de tomada de consciência de um campo do saber. Essa investigação se faz através da descrição de um arquivo e de seus discursos, compreendendo-os como uma série de acontecimentos ou eventos discursivos. Para Foucault (2005), o discurso é ação, é acontecimento, parte de uma construção discursiva que cristaliza determinados saberes ao longo do tempo. Na arqueologia, nós descrevemos as regras e normas às quais esse discurso obedece, explicitando-as.

A proposta arqueológica é fazer a descrição das formações discursivas, da análise das positividades, da demarcação do campo enunciativo. Não é intenção do método explicar o que as coisas são em si, nem a busca por uma verdade do objeto estudado, e, sim, compreender os próprios discursos como práticas que obedecem a regras. A AAD é uma estratégia especialmente eficaz na investigação de temas não hegemônicos, marginalizados por propostas de pesquisa ancoradas em paradigmas diferentes, pois é capaz de lançar luz ao que está obscurecido e passa despercebido em outras metodologias, ao que não é importante para elas.

A atuação específica da AAD é na linguagem, seja ela escrita, falada ou imagética, na camada específica do território arqueológico do discurso, a do enunciado: é aí que se encontram os sítios arqueológicos do discurso. "É na escavação, desses territórios de saberes, que é possível encontrar os artefatos enunciativos, a exemplo das ordens de discurso, das práticas discursivas, dos arquivos, das formações discursivas e das positividades" (Alcântara; Carlos, 2013, p. 64). A pesquisa que pretende analisar arqueologicamente um enunciado deve buscar as regularidades presentes na dispersão, procurando conhecer as séries enunciativas, os campos de domínio, as regras que constituem as formas ou os modos de existência do discurso estudado. De maneira resumida, a análise se faz no âmbito da linguagem, no território dos saberes, em busca dos artefatos enunciativos, a exemplo das práticas e ordens discursivas.

A pesquisa arqueológica é qualitativa e sua execução é prática, mas não é pragmática. O caráter prático é profundamente relacionado à reflexão teórica e não podem ser dissociados, por isso não é possível atribuir uma característica manualesca aos procedimentos da AAD, sendo ela, uma forma de pensar e agir durante toda a pesquisa. Foucault (2010) pontua que seu processo de investigação é baseado em três critérios, que identificam e sistematizam o universo do discurso estudado. São, segundo o autor, unidades que escandem, simultaneamente ou não, o universo desses discursos: (a) os critérios de formação - que permitem compreender que toda formação discursiva é única e individualizada, definida por um jogo de regras específico; (b) os critérios de transformação ou de limiar - que ajudam a definir a partir de que limiar de transformação novas regras foram postas em jogo; e (c) os critérios de correlação - que podem ser definidos como o conjunto de relações que situam esse discurso entre os outros e o contexto não discursivo no qual funciona. Sintetizando, o autor explica que seu método não procura, como a história tradicional, "detectar o espírito de uma época". Em vez disso, o que o autor intenta é compreender as relações e funções de um discurso. "Estudei alternadamente conjuntos de discursos; caracterizei-os; defini os jogos de 
regras, de transformações, de limiares, de remanências; eu os compus entre eles, descrevi os feixes de relações" (Foucault, 2010, p. 5).

O que o autor propõe é uma análise que abrace todos os tipos de transformações diferentes, em suas especificidades, rompendo com o raciocínio tradicional da continuidade, priorizando, em vez da linearidade dos fatos, as descontinuidades. "O importante é dar por conteúdo ao conceito monótono e vazio de 'mudança' um jogo de modificações especificadas" (Foucault, 2010, p. 7). Nesse jogo de relações, interessa a Foucault descobrir as transformações baseadas nas relações de dependências: intradiscursivas - entre os objetos, as operações, os conceitos de uma mesma formação; interdiscursivas - entre as formações discursivas diferentes; e extradiscursivas - entre as transformações discursivas e outras que só são produzidas no discurso.

Apesar de ser uma abordagem que descreve as leis gerais de ordenamento de um discurso, elas servem apenas para o discurso em questão e não para o universo dos discursos ou para qualquer objeto. Alcântara e Carlos (2013) explicam que as etapas da pesquisa arqueológica consistem no emprego de três procedimentos básicos: (a) o mapeamento das fontes, (b) a escavação da zona do discurso e (c) a análise e a descrição dos enunciados, que podem ser desmembrados em quatro etapas: (1) o ponto de partida da investigação, caracterizado por uma fonte específica selecionada pelo pesquisador a partir do mergulho no campo estudado; (2) a definição das fontes, com o mapeamento do campo, a seleção do universo de fontes e agrupamento do material em grupos de documentos com características similares; (3) a escavação das séries enunciativas, feita com as ferramentas disponibilizadas pela AAD; e (4) a comunicação dos achados, que só é possível após a seleção dos trechos que se constituirão enquanto corpus da pesquisa e cuja organização se dá a partir deles, bem como a representação visual desses achados, feita através do recurso das Árvores de Derivação Arqueológicas (ADAs). Ao final do processo, o que a arqueologia faz é uma reescrita do que já foi dito, do que já foi posto: "a descrição sistemática de um discurso-objeto" (Foucault, 2005, p. 157), deixando claras as ordens discursivas e séries enunciativas que organizam determinado discurso. Assim sendo, mergulhamos na obra de Dias (2018), que nos traz as primeiras propostas educacionais para o ensino de jornalismo no país, escavando o que ele dispõe a respeito do discurso sobre o ensino de fotografia nesses documentos.

\section{Resultados e Discussão}

Os documentos analisados neste trabalho são referentes às práticas pedagógicas sugeridas por diferentes entidades e grupos na primeira metade do século passado, período que se caracteriza por não terem sido implantados ainda os cursos de graduação em jornalismo no país, o que só se efetiva em $1950^{1}$. Chegamos a eles através do mapeamento do percurso que parte do relatório sobre as DCNs de 2013, publicado em 2009, que aponta para cursos e experiências pedagógicas. O nosso ponto de partida nos remonta às propostas de ensino datadas da primeira metade do século XX, compreendidos como experimentais, que existiram antes da implantação oficial dos cursos de jornalismo em nível superior no Brasil.

Ao traçar uma historicidade do ensino de jornalismo no país, o relatório das DCNs de 2013 nos leva para a proposta que teve início oficial em 1908, na Associação Brasileira de Imprensa. Esse é o trecho que nos encaminha a pesquisar as primeiras intenções pedagógicas para o ensino de jornalismo no país: "Já em 1908, Gustavo de Lacerda, ao fundar a Associação Brasileira de Imprensa - ABI, reivindicava uma escola de jornalismo para formar repórteres" (BRASIL, 2009, p. 8). Deste primeiro, seguiram-se outras, somando sete propostas até meados de 1950, seis delas analisadas neste trabalho.

Esse grupo específico de documentos é de difícil acesso, não está disponível on-line, tampouco identificamos livros que trazem os textos na íntegra. Porém, tivemos conhecimento de parte de seu conteúdo através do livro de Dias (2018), que

\footnotetext{
${ }^{1}$ O Decreto-lei $n^{\circ} 910$ de 1938, que dispunha sobre a duração e condições do trabalho em empresas jornalísticas, foi o primeiro a citar a obrigatoriedade do diploma para o exercício do jornalismo no país (BRASIL, 1938), mas apenas em 1943 o Decreto-lei n 5.480 (BRASIL, 1943) institui o curso de jornalismo no sistema de ensino superior brasileiro. Só em 1950 entra em funcionamento o curso superior de jornalismo das Faculdades Cásper Líbero, em São Paulo, o primeiro do país.
} 
investigou publicações de imprensa e acervos privados em um levantamento sobre as primeiras propostas de ensino de jornalismo no país, analisando fontes de 1908 a 1958, sendo selecionados aqui apenas aqueles que se efetivaram em documentos até 1950. Apesar de não podermos analisar as formações discursivas em profundidade no texto que Dias (2018) apresenta, já que ele não traz os documentos na íntegra, é possível identificar, pelo menos, a presença e a ausência do discurso sobre o ensino de fotografia neste período, o que colabora de forma marcante no entendimento de que a imagem fotográfica sempre se fez presente na compreensão pedagógica do ensino de jornalismo no Brasil. No grupo de cursos que identificamos no livro, fizemos outra subdivisão: aqueles que se referem às propostas em nível de graduação ou similar a uma formação em nível superior; e aqueles cursos livres, de curta duração ou por correspondência.

O conjunto de fontes analisadas neste artigo pode ser visualizado na Árvore de Derivação Arqueológica² (ADA) a seguir (Figura 1), uma representação visual dos caminhos da pesquisa proposta por Foucault (2005), que demonstra o percurso trilhado nesse grupo de fontes, bem como a rede de aparecimentos discursivos da fotografia, nosso objeto de estudo. Este grupo de documentos apresenta séries enunciativas importantes para compreensão do discurso sobre o lugar que o ensino de fotografia ocupa nesse contexto, mostrando que ele está incluso desde as primeiras intenções pedagógicas para a formação jornalística no Brasil.

Dias (2018) explica que inúmeras tentativas de implantar cursos de jornalismo no Brasil aconteceram desde a primeira ideia, em 1908, até 1947. Eram, na maioria, iniciativas de capacitação como extensões universitárias, formações que partiam da Igreja Católica ou de grupos profissionais, até mesmo formações por correspondência. Através de pesquisa na imprensa da época e de acervos particulares, o autor traz em seu livro as estruturas curriculares e comentários sobre seus conteúdos e os contextos em que foram produzidos. Na obra, o autor publica as disciplinas ofertadas nessas propostas, cuja maior parte nunca chegou a funcionar.

O pesquisador encontra sete propostas curriculares antes da implantação dos cursos superiores, sendo elas datadas de 1918, 1933, 1935, 1942, 1943, 1944 e um curso por correspondência que teria circulado pelo país em um período não especificado entre os anos 1940 e 1950. O projeto lançado em 1908 pela Associação Brasileira de Imprensa, cuja proposta pedagógica ficaria pronta apenas em 1918, conta com um conjunto de conteúdos que objetivavam dar aos alunos o ensino das matérias compreendidas como essenciais à prática da profissão, com a teoria e a prática. Esse primeiro modelo seria diretamente inspirado por um curso que existia na Universidade de Missouri, nos EUA, que disporia também de um jornal escolar como prática pedagógica. Era uma formação de quatro anos, sendo os dois primeiros com conteúdos voltados para as áreas de ciências e artes, e os dois últimos para capacitação no jornalismo propriamente dito. Dias (2018) explica que ele estabelecia o perfil do egresso como:

1) estar preparado teoricamente por meio das aulas do 'curso vestibular' e do 'curso geral'; 2) estar versado e traquejado na vida de imprensa por meio da prática no 'jornal escolar', espelho fiel do ambiente em que trabalharão; 3) saber escrever tudo; 4) conhecer todos os trabalhos de oficinas, revisão e administração; 5) ser capaz de redigir anúncio vistoso em prosa ou verso, com vinhetas ou gravuras; 6) conhecer o comércio, os políticos, os administradores, os artistas, tendo frequentado salões, teatros, sacristias, cabarés e restaurantes (DIAS, 2018, p. 42).

\footnotetext{
${ }^{2}$ A importância das ADAs como ferramenta metodológica bem como a aplicação da metodologia da AAD no estudo do discurso sobre o ensino de fotografia nos cursos de jornalismo do Brasil foi aprofundada no trabalho intitulado "O ensino de fotografia nos documentos educacionais de jornalismo através da análise arqueológica do discurso" (AQUINO, 2020), que traz uma série de gráficos que ilustram o percurso da fotografia em documentos históricos nacionais e regionais, com destaque para os projetos pedagógicos dos cursos de jornalismo paraibanos.
} 
Figura 1

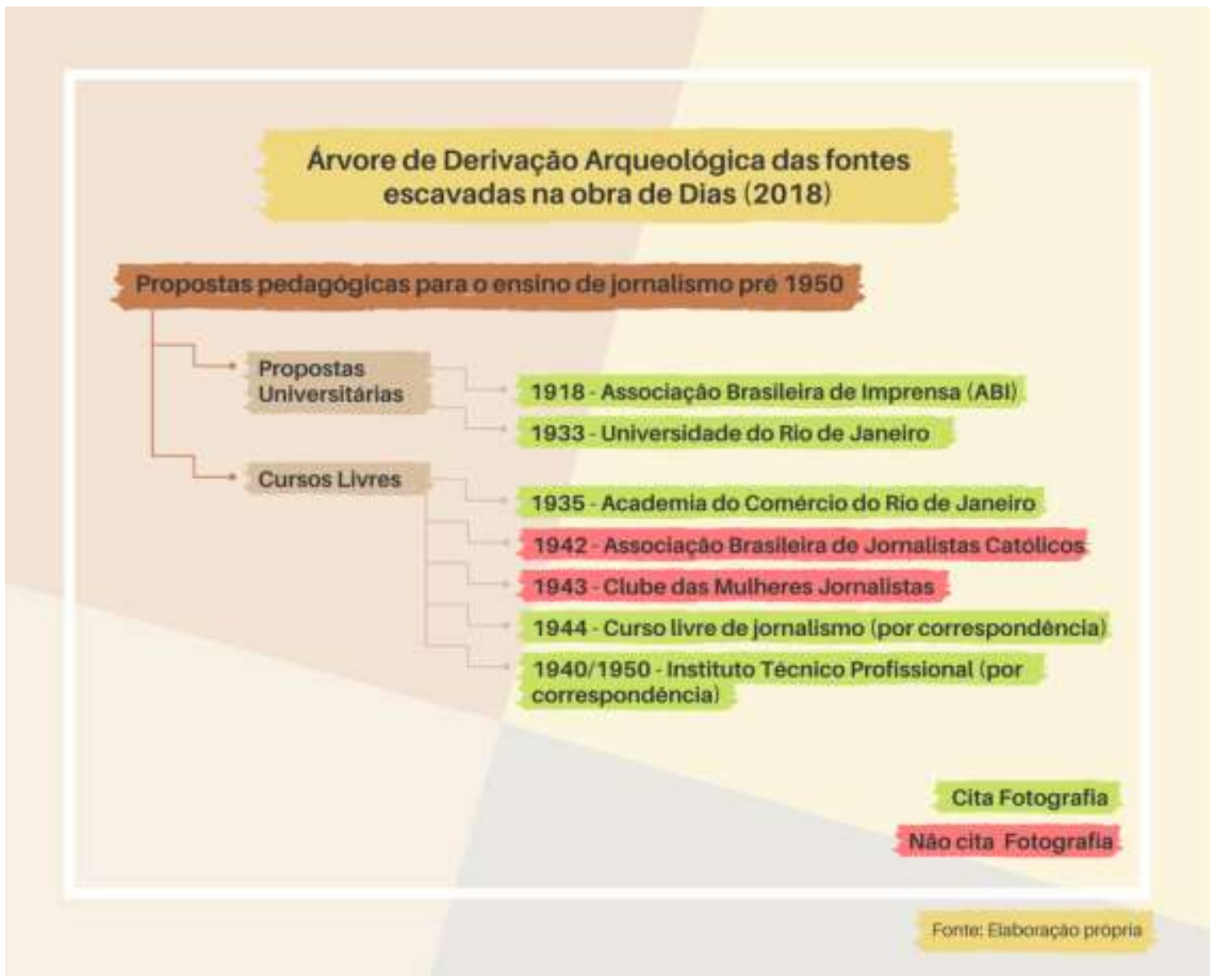

Fonte: Autores.

Percebemos, por esse trecho, que há um discurso que fortalece a formação centrada na escrita, além da necessidade de conhecimento de espaços e comportamentos sociais diversos para o exercício do jornalismo, bem como um mergulho na vida cultural, sacra e profana, do contexto social em que o jornalista estivesse inserido. $\mathrm{O}$ autor traz também a lista de atividades da formação prática através do jornal escolar, cuja finalidade seria:

1) desenvolver a prática na sintaxe e na ortografia da língua; 2) redigir reportagens mundanas, artísticas, policiais e sociais; 3) redigir artigos de política; 4) redigir artigos de finanças [economia]; 5) fazer crítica de música, pintura, teatro e literatura; 6) aprender artes gráficas: tipografia, linotipia, revisão, paginação, estereotipia e impressão de jornal e 7) aprender fotografia e gravura (DIAS, 2018, p. 42-43, grifo nosso).

Apesar de nunca ter sido posto em prática, o curso demonstra interesse na formação também para além da escrita e da redação, incluindo as chamadas no texto de "artes gráficas", com destaque para o trecho que cita "aprender fotografia e gravura". Mesmo sendo uma proposta curricular que acontecia apenas algumas depois da publicação da primeira foto na imprensa escrita do país, ela já compreende a comunicação visual e fotográfica como importante para formação. Ainda que de forma não detalhada, sem o mesmo status da escrita (com menor aparição e em um contexto discursivo que a coloca enquanto prática de uma atividade laboratorial), a fotografia se faz presente na primeira proposta pedagógica para o ensino de jornalismo no Brasil e, mais importante, como algo que o jornalista em formação deveria aprender e não apenas conhecer.

Outro documento analisado, concebido em 1932 e publicado um ano depois, em 1933, a formação de Extensão Universitária da Universidade do Rio de Janeiro era um curso que "seria regido por profissionais do jornalismo e as aulas 
aconteceriam na sede da Associação Brasileira de Imprensa" (Dias, 2018, p. 75). O programa pedagógico foi publicado na Revista da Universidade do Rio de Janeiro e era planejado em duas partes: "um curso teórico ministrado por meio de conferências, com duração de dois anos, e um curso prático com dez alunos por turma, planejado para acontecer na forma de seminário. Também com duração de dois anos" (Dias, 2018, p. 75).

Somando um total de quatro anos de duração e com uma proposta que pretendia uma formação que recorre ao termo "superior", mesmo que ainda não atrelado às nomenclaturas de graduação ou bacharelado, era um curso com conteúdos divididos entre dois tipos: teóricos e práticos, ministrados paralelamente no decorrer das aulas. Os conteúdos teóricos abordavam desde a redação, passando por ciências, conteúdos de história e do direito, além de sociologia, lógica, saúde, educação e filosofia. Literatura, música, artes em geral, publicidade, economia e solidariedade também eram abordados, como vemos no trecho que detalha os componentes curriculares teóricos:

[Teóricas do primeiro ano] Redação e composição (jornalística); Ciências físico-químico (sic) e naturais em sua aplicação diária; História europeia atual - O momento asiático; História da civilização brasileira - O momento americano; História do Jornalismo - direito e Legislação Jornalística - Ética Jornalística; Sociologia e lógica; Assistência social - Educação higiênica; Pedagogia social - Educação política, Filosofia geral - Filosofia Política. [Teóricas do segundo ano] Pensamento moderno - Estudo crítico do mundo moderno - Vida literária; Análise artística - Conhecimento e interpretação dos críticos contemporâneos - Música e artes mórficas; Métodos de Publicidade Difusão jornalística; Jornalismo Internacional - Assuntos diplomáticos; Crítica diária - Problemas de atualidade (trabalho, economia, finanças, educação); Administração de jornal; Solidariedade jornalística - Associação de Imprensa - Previdência - Mutualidade (DIAS, 2018, p. 76).

Já a parte prática do curso era ministrada de forma conjunta com a teórica, e não posteriormente à teoria como se solidificou no ensino de Comunicação Social a partir de 1969. As disciplinas práticas eram chamadas de "curso prático", composta por conteúdos que iam desde a leitura de obras de escritores e de documentos, bem como a redação de textos jornalísticos dos mais diversos gêneros e da compreensão da psicologia. A fotografia não estava de fora:

[Práticas do primeiro ano] Leitura e análise dos escritores contemporâneos (Teatro, romance, história); Leitura e análise dos documentos políticos contemporâneos (trabalho, comércio, indústria, economia, finanças); Relação sintática (notícias resumidas, histórias curtas, artigos de magazine); Prática da imprensa moderna (organização do jornal, disposição da matéria, anúncios, ilustrações, legendas e cabeçalhos). [Práticas do segundo ano] Prática de reportagem artística; Prática da reportagem política; Prática da reportagem social e esportiva; Redação e reportagem policial; Prática tipográfica; Escrituração mercantil; Prática do artigo editorial (aplicação das leituras e análises); Artes dos desenhos e das fotografias aplicadas à imprensa; Psicologia do título e subtítulo; A psicologia do assunto (DIAS, 2018, p. 77, grifo nosso).

A fotografia se faz presente nessa proposta de formação de uma maneira específica: compreendida como uma forma de arte aplicada à imprensa e não aquilo do que se trata realmente o fazer jornalístico. É possível identificar nas listas de disciplinas alguns enunciados como o da centralidade da formação para a escrita, o da importância de uma formação humanística, a separação entre a teoria e a prática, apesar de relacionadas, além da presença da fotografia à margem da formação principal do jornalismo, que seria a redação. Também identificamos que, nesses documentos, as pessoas habilitadas a ministrarem os conteúdos são os profissionais da imprensa e a escrita é compreendida como uma atividade prática, porém de cunho intelectual.

Em 1935, a Academia de Comércio do Rio de Janeiro criou um curso de formação livre, também não implantado, que teria duração de dois anos, com cada disciplina vinculada a uma atividade prática, a exemplo do conteúdo de Língua Portuguesa e literatura em geral e especialmente brasileira que era atrelado à prática de reportagem. 
Na medida em que o sujeito estudava a língua e a literatura, ele praticava a reportagem, a resenha de livros e a crítica cultural. A própria disciplina, ao mesmo tempo em que dispunha para o aluno a habilidade no conhecimento da língua e literatura, requeria dele a prática e a competência para redigir esses formatos jornalísticos específicos (Dias, 2018, p. $81)$.

Os conteúdos desse curso eram divididos entre básicos do primeiro e do segundo anos e uma lista com seis cadeiras facultativas. No primeiro ano, eram ministrados conjuntamente conteúdos práticos e teóricos que se complementavam, estavam intercalados e amarrados uns aos outros, a exemplo do estudo de línguas estrangeiras atrelado a uma prática de correspondente externo. $\mathrm{O}$ fragmento a seguir que traz as disciplinas desse que seria o primeiro momento da formação:

Português e literatura em geral e especialmente brasileira (Teórica) e Prática de reportagem e de bibliografia Prática e de crítica literária (Prática); Francês ou Inglês (Teórica) e Prática de tradução de jornais e de revistas, Prática de reportagens para o exterior, Prática de correspondentes de jornais externos (Prática); Geografia Geral e Geografia Política especialmente do Brasil (Teórica) e Prática de reportagens de excursões e de viagens (Prática); Direito Constitucional, Direito Internacional (noções) e Legislação do trabalho (Teórica) e Prática de reportagens política e religiosa (Prática); Direito Privado (civil e comercial, noções) (Teórica) e Prática de reportagem social e esportiva (Prática); Direção geral de jornais (Teórica) e Prática de entrevistas, Redação de noticiário, Revisão tipográfica, Retranca e Noções sobre material gráfico especialmente dos quotidianos (Prática); Propaganda e publicação em geral (Teórica); e Ética do Jornalismo (Teórica) (Dias, 2018, p. 82).

O modelo que liga conteúdos teóricos a práticos, como duas etapas da mesma matéria, se repete no segundo ano da formação. Ele demonstra uma forma particular e específica de interligar os conteúdos, modelo que não foi seguido por propostas posteriores, como a vinculação de atividades práticas de reportagem policial e judiciária à disciplina teórica de Leis de imprensa e segurança social. Esse relacionamento da teoria com a prática segue com outros conteúdos, inclusive imagéticos, como é possível conferir na lista de disciplinas do segundo ano do curso:

Economia Política e Finanças (noções), Legislação Fiscal e Estatística (Teórica) e Prática de Reportagem Financeira, comercial e industrial, Reportagem dos grandes estabelecimentos da indústria e do comércio e das respectivas repartições públicas(Prática); Direito criminal (noções), Organização judiciária (noções), Processo penal (noções), Crítica de Jurisprudência, Leis de imprensa e de segurança social (Teórica) e Prática de reportagem policial e judiciária (Prática); Desenho e caricatura (Teórica) e Prática de reportagem gráfica a lápis e Prática fotográfica, Gravura em sua várias modalidades (noções) (Prática); Noções de arte em geral (Teórica) e Prática de Reportagem e de crítica artística especialmente em exposição de pintura, teatro, cinemas e concertos (Prática); Organização de Arquivo Jornalístico, Interpretação de telegramas, Distribuição de trabalho, Crítica dos originais a publicar, Orientação da paginação, Edições sucessivas, Providências de emergência (Teórica) e Prática de Secretário de Redação (Prática); Jornalismo doutrinário, Polêmica, Administração, Imprensa interna e externa, Associações e sindicatos jornalísticos (Teórica) e Prática da direção geral (Prática); e Publicidade e especialmente gráfica (Teórica); e Ética Geral, especialmente do alto jornalismo (Teórica) (DIAS, 2018, p. 83-84, grifo nosso).

Identificamos, nessa proposta de formação acadêmica, uma característica particular na forma de lidar com a distribuição dos conteúdos teóricos e técnicos: associando-os diretamente um ao outro, como material uníssono, duas faces da mesma moeda. Também é possível, através da estrutura curricular, perceber a força da formação para a escrita, do conteúdo de humanidades e, ainda, da presença das formas visuais do jornalismo, identificadas através não só da fotografia, como também do desenho e da caricatura. Nessa estrutura, a fotografia é colocada como uma forma de ilustração do jornalismo: uma prática fotográfica. A proposta educativa também trazia uma lista com seis cadeiras de caráter facultativo, composta por idiomas e técnicas manuais de lidar rapidamente com o texto e a escrita, como a datilografia e a estenografia, todas de caráter prático: "Estenografia aplicada ao jornalismo, Datilografia aplicada ao jornalismo, Estenotipia aplicada ao jornalismo Prática, Alemão aplicado ao jornalismo, Italiano aplicado ao jornalismo Prática e Espanhol aplicado ao jornalismo" (Dias, 2018, p. 84). Nesta fonte, o conteúdo de fotografia, mesmo aparecendo em quantidade menor e associada ao desenho e à caricatura, está junto aos 
conteúdos de caráter obrigatório e compreendidos como parte do fazer jornalístico, enquanto as práticas mais manuais, como estas últimas, estão separadas em conteúdos opcionais, dando à fotografia um status de importância na educação do jornalista em formação.

Dias (2018) conta que, entre 1935 e 1937, existiu também um projeto de curso da Universidade do Distrito Federal, no Rio de Janeiro, feito pelo educador Anísio Teixeira, mas que não chegou a ser implantado, sendo frustrado pelo golpe do Estado Novo, de Getúlio Vargas. O livro de Dias (2018) não traz de forma detalhada essa proposta curricular, portanto, não conhecemos o seu conteúdo e nem sabemos se a fotografia estava presente, ficando então ausente da análise. Em 1942, entraria em funcionamento um curso da Associação Brasileira de Jornalistas Católicos. Planejado desde 1934, ele oferecia aulas duas vezes por semana e consistia de reflexões teóricas acompanhadas, quando oportunamente, de visitas a organizações jornalísticas.

Ao investigar a grade curricular, percebe-se que as grandes temáticas do ensino de jornalismo são coincidentes. História, Ética e Legislação do Jornalismo parecem ser preocupações primordiais. [...] No caso específico do elenco de disciplinas desse curso criado pela Igreja Católica, aparece pela primeira vez "Filosofia da Imprensa" sob os cuidados de um padre (Dias, 2018, p. 89).

O autor explica que era uma formação que visava um forte senso de responsabilidade baseado nos princípios da American Society of Newspaper Editors, que passaram a ser conhecidos no mundo como os primeiros cânones do jornalismo, "uma espécie de código de conduta para todo e qualquer jornalista" (DIAS, 2018, p. 90). A matriz curricular consistia em oito conteúdos:

História do Jornalismo - particularmente no Brasil; A arte da palavra, aplicada à imprensa; A Técnica do jornal; A administração do jornal; A ética do Jornalismo; Legislação de Imprensa; Filosofia da Imprensa e psicologia da notícia; e A técnica da publicidade aplicada à Imprensa (Dias, 2018, p. 88-89).

O que este breve currículo demonstra para esta pesquisa é sua forte carga humanística e filosófica, moral e ética, distanciada de uma prática jornalística. É um modelo de curso que funcionaria como capacitação complementar para os interessados na profissão, por um viés de interesse religioso. Não apresenta conteúdos da prática profissional e a fotografia também não está inclusa.

Em 1943, é criado, no Rio de Janeiro, o ‘Clube das mulheres jornalistas', composto por aquelas que atuavam ou tinham interesse de atuar na profissão. Dessas reuniões, surge um curso de jornalismo exclusivo para mulheres, composto por quatro disciplinas e frequentado por "professoras, escritoras e senhoritas da melhor sociedade carioca" (Dias, 2018, p. 93). O autor explica que não foi possível encontrar o currículo completo e o material que teve acesso mostrava apenas os conteúdos de Jornalismo Moderno, Psicologia, A Educação na defesa nacional e A mulher jornalista na guerra. Assim como a formação proposta pela Igreja Católica, não identificamos atividades de cunho prático ou profissionalizante entre seus conteúdos, como também não há referências à imagem fotográfica. Esses dois cursos são os únicos do grupo analisado que não trazem a fotografia em seus projetos pedagógicos, bem como outras práticas. Este último, voltado para o público feminino, não está disponibilizado completamente o que torna impossível identificar através escavação arqueológica do discurso se eles compreendiam a fotografia como conteúdo necessário à formação.

Dias (2018) conta que as principais iniciativas de ensino de jornalismo no país da década de 1940 são cursos por correspondência, dentre eles o de 1944, organizado através de fascículos e promovido por Vitorino Prata Castelo Branco. Tinha duração de um ano e era organizado em quatro aulas (chamadas de pontos) por mês, subdividido em tópicos semanais. "O ponto da semana, relativamente pequeno, raramente passava de duas páginas. Ao final de cada mês, havia uma prova" 
(Dias, 2018, p. 95). O "Curso Livre de Jornalismo" era uma cópia adaptada de um curso nos mesmos moldes que se tornou popular nos EUA, organizado em três eixos fundamentais: técnica jornalística, história do jornalismo e uma parte prática que consistia em provas mensais, no que o proprietário chamava de "escola circulante", com proposta de curso rápido e objetivo. Elencava 36 pontos da "técnica jornalística", com conteúdos que abordavam desde generalidades, passando pela arte de escrever, o poder da imprensa, a responsabilidade do jornalista, a organização interna da redação, os diferentes gêneros da reportagem, títulos e subtítulos, a influência americana nos jornais brasileiros, o conceito de notícia e o "lead", o comentarista e o crítico, sindicatos, esportes, "páginas femininas", o diário oficial, economia e publicidade de um jornal, como escolher o nome da publicação, o formato, o uso de marca d'água, o registro profissional, o uso do papel, a vida social, a publicação de clichês, orientação política e o papel do jornalismo na sociedade, a administração e os lucros de um jornal, organização hierárquica de um jornal, agências de notícias, serviços telegráficos, o arquivo e até mesmo bases para o guarda-livros. A fotografia estava incluída na aula de número 14 "A reportagem fotográfica, Requisitos necessários, Conselhos aos repórteres principiantes" (Dias, 2018, p. 107, grifo nosso).

Identificamos nessa extensa lista de conteúdos que a prática, mesmo em uma formação não presencial, fazia parte de forma marcante da proposta, inclusive com conteúdos voltados para fotografia, como grifado no trecho acima, demonstrando a importância da compreensão fotográfica para o jornalismo, mesmo em um curso por correspondência. A formação também tinha outros eixos como História do Jornalismo, subdividido em 12 conteúdos, além de 37 aulas complementares, que versavam sobre temas diversos, como propaganda, censura, corpos tipográficos e a mulher no jornalismo. Era uma proposta que abarcava uma grande quantidade de temas humanísticos, cotidianos e sociais.

Um segundo curso por correspondência teria sido ofertado pelo 'Instituto Técnico Profissional', que funcionava no Rio de Janeiro. Dias (2018) explica que teve dificuldade em precisar detalhes como encarregados do curso ou mesmo o período de atuação, sabendo sobre ele o que foi encontrado nos fascículos circulados nas páginas do Correio da Manhã. A proposta de formação prometia um processo rápido de aprendizagem, traduzido e adaptado do modelo norte-americano $L a$ Salle University, e era dividido em 48 semanas, de 48 aulas cada, com três eixos principais: 1) técnica de jornalismo, 2) extensão cultural, onde a fotografia estava incluída, 3) ética, organização e administração de jornal, legislação de imprensa e história do jornalismo no Brasil, como transcrito em detalhes a seguir:

Eixo 1 - Técnica de jornalismo: Redação de notícias; Como se faz uma notícia; Títulos e manchetes; A entrevista; O repórter e a reportagem; A paginação; A redação radiofônica (DIAS, 2018, p. 129). [...] Eixo 2 - Extensão cultural: O campo do jornalismo; O jornalismo como vocação; Nomes que fazem notícias; Notícias sobre discursos; O estilo do jornal; As notícias de crimes; O projeto cívico é notícia; A imprensa e o esporte; Os negócios como notícia; A marcha da ciência como notícia; A política como notícia; As mulheres no jornalismo; O calendário como notícia; Colunas e colunistas; O feature; As agências mundiais de informação; As agências nacionais de informação; A fotografia jornalística; A crítica; O editorial; Normas práticas de redação jornalística; A mecânica da publicação (IDEM, p. 140, grifo nosso). [...] Eixo 3 - Ética, organização e administração de jornal, legislação de imprensa e história do jornalismo no Brasil: Ética; Organização e administração de jornal; Legislação de imprensa, tipografia e jornalismo no Brasil: primeiras tentativas; Hipólito da Costa e o Correio Braziliense, Jornalismo contemporâneo de Hipólito da Costa; $\mathrm{O}$ jornalismo fluminense da independência; $\mathrm{O}$ jornalismo provinciano da independência; $\mathrm{O}$ jornalismo nos Estados; Evaristo da Veiga e a Aurora Fluminense; Alguns jornais e jornalistas do Segundo Império (Dias, 2018, p. 154).

Essa proposta que, segundo Dias (2018), teria circulado pelos correios no país entre os anos 1940 e 1950, dá ênfase aos conteúdos que trazem o fazer jornalístico como foco, tanto na escrita como na compreensão dos contextos sociais e culturais necessários para o exercício do jornalismo. A fotografia é apresentada como material jornalístico, em uma sequência de tópicos que não a difere dos outros conteúdos necessários à formação, se apresentando como uma proposta pedagógica que 
compreende a fotografia como conteúdo necessário a formação do jornalista. Relaciona diretamente a fotografia ao jornalismo ao usar a expressão "fotografia jornalística".

\section{Considerações Finais}

Mesmo não sendo possível, por falta de acesso aos documentos na sua extensão completa, saber que posição detalhada os conteúdos de fotografia ocupam no discurso desses documentos, nem mesmo a compreensão que as fontes dão à imagem fotográfica, como vimos, mesmo antes da oficialização dos cursos de formação superior no país, a fotografia já se fazia presente na maior parte das propostas pedagógicas existentes até então. Se levarmos em conta apenas aqueles que se propunham a ser uma formação com características similares a uma graduação, a fotografia está presente nas duas.

Outra compreensão que podemos fazer desse conjunto de documentos é que eles têm uma grande presença de conteúdos voltados à prática profissional, além de uma forte influência dos modelos de ensino norte-americanos da época, em uma contradição ao que está posto nos Currículos Mínimos para os cursos de Comunicação Social de 1977 e 1984, que afirmam que os cursos anteriores a essas datas eram prioritariamente teóricos e baseados em modelos europeus.

Dias (2018) traz os fluxogramas e algumas informações pontuais sobre público aos quais esses cursos seriam destinados, além do perfil do egresso e do período de funcionamento. Assim, pudemos identificar algumas características das primeiras propostas pedagógicas para o ensino de jornalismo no país, mesmo que a maioria delas nunca tenha funcionado efetivamente, mas que têm a capacidade de demonstrar o pensamento pedagógico sobre o ensino de jornalismo da época. Nesse grupo de documentos, datados da primeira metade do século XX, há uma ênfase à escrita como meta da formação, bem como uma regularidade na prática profissional e na referência ao mercado e no jornalista como conhecedor de diversos assuntos, detentor de uma cultura geral. Já na primeira proposta, lançada em 1908 pela Associação Brasileira de Imprensa e estruturada em 1918, há a citação à fotografia como conteúdo para formação do jornalista. O curso proposto em 1933 como Extensão Universitária da Universidade do Rio de Janeiro também incluía "Artes dos desenhos e das fotografias aplicadas à imprensa". Essas são as duas propostas de cursos de longa duração desse período, com quatro anos de estudos cada, com estrutura similar a uma formação em nível de graduação. Elas revelam uma compreensão da fotografia como parte da formação do jornalista já na primeira metade do século passado. Mesmo não demonstrando ser o foco principal da capacitação do profissional, a fotografia se fazia presente nos conteúdos obrigatórios.

Os outros cursos dessa primeira fase do ensino de jornalismo no país são os avulsos, de curta duração ou por correspondência, somando cinco propostas. Delas, três trazem a fotografia expressa em suas linhas, nos cursos de 1935, 1944 e no que teria circulado por correspondência no país entre 1940 e 1950, sem data precisa. Mesmo que de forma pontual, colocada como ilustração do jornalismo, como técnica e prática. Há, no de 1944, a referência à expressão "reportagem fotográfica" como um de seus conteúdos, atrelando diretamente a fotografia ao fazer jornalístico. O outro curso por correspondência também faz referência direta ao conteúdo chamado "A fotografia jornalística", e não à fotografia em geral, apontando para o universo específico do fotojornalismo. Ambos foram baseados em modelos de ensino a distância que circulavam nos EUA, país com tradição de pragmatismo no ensino e no mercado jornalísticos. Os outros dois cursos, de 1942 e 1943, eram propostas de curta duração, com poucos conteúdos, sem detalhamento e a fotografia não aparece entre eles. Mas é possível compreender que, na dispersão dos documentos, há uma regularidade da presença da fotografia nas propostas pedagógicas que fundam o ensino de jornalismo no país, mesmo que de maneira marginal. Isso contradiz o que está posto nas atuais DCNs para o ensino de jornalismo no país, que, como explanado na introdução, excluem a fotografia de suas linhas.

É importante destacar também que, diferente do que aconteceu com o período em que o curso de jornalismo deixou de existir de forma independente para fazer parte das habilitações de comunicação social, de 1969 a 2013, onde, segundo Meditsch (2012), houve um apagamento das especificidades do jornalismo em detrimento de uma teoria mais genérica da área, 
o período analisado aqui traz propostas pedagógicas que abraçam a prática e estão definitivamente voltados ao fazer jornalístico. E a fotografia faz parte dele.

As informações dessa investigação podem servir como ponto de partida para outras abordagens de pesquisa, a exemplo do estudo sobre a fotografia nas documentações de cunho legislatório ao longo do tempo, da análise do estado discursivo da fotografia nos cursos de jornalismo hoje, bem como servir de base para novas propostas pedagógicas que abordem o fotojornalismo de forma mais igualitária com relação a outras áreas de atuação profissional do jornalista.

\section{Referências}

Alcântara, M. A. M., \& Carlos, E. J. (2013). Análise Arqueológica do Discurso: uma alternativa de investigação na Educação de Jovens e Adultos (EJA). Intersecções: revista de Estudos sobre Práticas Discursivas e Textuais, Jundiaí/SP, http://www.anchieta.br/unianchieta/revistas/interseccoes/pdf/Interseccoes_Ano_6_Numero_3.pdf.

Aquino, A. P. P. (2018). Jornalismo sem foco: a ausência da fotografia nas novas diretrizes do Mec para os cursos de jornalismo. ANAIS do XXIV Encontro de Pesquisa Educacional do Nordeste - Reunião Cientifica Regional da ANPEd. Universidade Federal da Paraíba. http://anais.anped.org.br/regionais/sites/default/files/trabalhos/12/3837-TEXTO_PROPOSTA_COMP LETO.pdf.

Aquino, A. P. P. (2020). O ensino de fotografia nos documentos educacionais de jornalismo através da análise arqueológica do discurso. Revista Brasileira de Ensino de Jornalismo, Brasília, 10 (27), 19-35. http://rebej.abejor.org.br/index.php/rebej/article/view/393.

Aquino, A. P. P. (2021). Uma arqueologia do discurso sobre o ensino de fotografia no bacharelado em jornalismo no Brasil: o status marginal do fotojornalismo. 252 f. Tese (Doutorado em Educação) - Programa de Pós-graduação em Educação, Universidade Federal da Paraíba.

Brasil. (1938). Decreto-lei $n^{o}$ 910, de 30 de novembro de 1938. Dispõe sobre a duração e condições do trabalho em empresas jornalísticas. https://www2.camara.leg.br/legin/fed/declei/1930-1939/decreto-lei-910-30-novembro-1938-349925-publicacaooriginal-1-pe.html.

Brasil. (1943). Decreto-lei $n^{\circ} 5.480$, de 13 de maio de 1943. Institui o curso de jornalismo no sistema de ensino superior do país, e dá outras providências. https://www2.camara.leg.br/legin/fed/declei/1940-1949/decreto-lei-5480-13-maio-1943-415541-publicacaooriginal-1-pe.html.

Brasil. (1969). Resolução $n^{\circ} 11$, de 6 de agosto de 1969. Fixa os mínimos de conteúdo e duração do curso de Comunicação Social. In: Brasil. Currículo de Comunicação Social. Presidência da República. Circulação Interna.

Brasil. (1977). Parecer CFE no . 1.203/77, de 5 de maio de 1977. Currículo mínimo do curso de Comunicação Social. In: Brasil. Currículo de Comunicação Social. Presidência da República. Circulação Interna.

Brasil. (1984). Resolução $n^{\circ}$ 002, de 24 janeiro de 1984. Fixa o Currículo Mínimo de Comunicação Social, e dá outras providências. In: Brasil. Currículo de Comunicação Social. Presidência da República. Circulação Interna.

Brasil. (2009). Portaria $n^{o}$ 203, de 12 de fevereiro de 2009. Dispõe sobre as Diretrizes Curriculares Nacionais para o Curso de Jornalismo. http://portal.mec.gov.br/dmdocuments/documento final_cursos_jornalismo.pdf.

Brasil. (2013). Parecer CNE/CES $n^{o}$ 39, de 20 de fevereiro de 2013. Diretrizes Curriculares Nacionais para o Curso de Graduação em Jornalismo. http://portal.mec.gov.br/index.php?option=com_docman\&view=download\&alias=13063-pces039-13-pdf\&category_slug=maio-2013-pdf\&Itemid=30192.

Buitoni, D. S. (2010). Fotojornalismo e Ilustração: Imagens de Crianças na Mídia Impressa. In: XXXIII Congresso Brasileiro de Ciências da Comunicação, Intercom, 2010, Caxias do Sul. http://www.intercom.org.br/papers/nacionais/2010/resumos/R5-1985-1.pdf.

Buitoni, D. S. (2011). Fotografia e jornalismo: a informação pela imagem. Saraiva.

Carlos, E. J. (2017). Achados sobre a Noção Arqueológica do Discurso em Foucault. Dialectus, 4 (11), 176-191. http://periodicos.ufc.br/dialectus/article/view/31008/71632.

Dias, P. R. (2018). Gênese do ensino de Jornalismo no Brasil: Influências norte-americanas (1908-1985). Letras Contemporâneas.

Foucault, M. (2005). A arqueologia do saber. Forense Universitária.

Foucault, M. (2010). 1968 - Resposta a uma questão. In: Repensar a política. Coleção ditos e escritos VI. Forense Universitária, p. 1-24.

Foucault, M. (2016). As palavras e as coisas. Martins Fontes.

Louzada, S. (2004). Ascensão e queda de O Cruzeiro e Manchete. Observatório da Imprensa, 263. http://www.observatoriodaimprensa.com.br/diretorioacademico/ascensao-e-queda-de-o-cruzeiro-e-manchete/.

McLuhan, M. (1977). Entrevista concedida ao Mondey Conference on ABC TV em 27 de junho de 1977, com o tema "The medium is the message". 1 vídeo (43 min. e 46 seg.) https://www.youtube.com/watch?v=RX-Gqa3_XpU.

Meditsch, E. (2012). Pedagogia e pesquisa para o jornalismo que está por vir: a função social da universidade e os obstáculos para a sua realização. Insular.

Mick, J., \& Lima, S. (2013). Perfil do jornalista brasileiro: características demográficas, políticas e do trabalho do jornalista em 2012. Insular. 